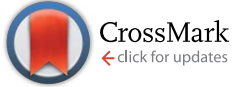

Cite this: RSC Adv., 2017, 7, 12945

Received 13th December 2016 Accepted 17th February 2017

DOI: 10.1039/c6ra28163j

rsc.li/rsc-advances

\section{Isatin thiosemicarbazones promote honeycomb structure formation in spin-coated polymer films: concentration effect and release studies $\uparrow$}

\author{
V. García Fernández-Luna,,$^{a}$ D. Mallinson, $\star^{a}$ P. Alexiou, ${ }^{b}$ I. Khadra, ${ }^{a}$ A. B. Mullen, ${ }^{a}$ \\ M. Pelecanou, ${ }^{\text {b }}$ M. Sagnou*b and D. A. Lamprou*ac
}

Formation of ordered porous polymer films is one of the techniques currently under investigation for its potential for the manufacturing of coatings with biomedical applications. Aiming for films with improved characteristics against bacterial colonization, poly(methyl methacrylate) (PMMA) and polyurethane (PU) films were formed via the spin coating method on silica wafer (SW) substrates, in the absence or presence of four isatin thiosemicarbazone derivatives (ITSCS) in various concentrations. The resulting films exhibited high hydrophobicity based on contact angle goniometry measurements ranging from minimum water contact angle values of $84.0^{\circ} \pm 4.0$ for PMMA and $85.0^{\circ} \pm 0.2$ for PU, alone, to a maximum of $129.3^{\circ} \pm 2.6$ and $102.1^{\circ} \pm 1.4$, respectively, after the addition of an ITSC. Atomic force microscopy revealed rough polymer surfaces with honeycomb structures which are affected by ITSC type and concentration. PMMA films presented a higher density of pores with a smaller pore diameter (280 $\pm 20 \mathrm{~nm}$ ) compared to PU films (647 $\pm 54 \mathrm{~nm}$ ). A $24 \mathrm{~h}$ dissolution study showed a gradual release of ITSC from the PMMA film, in a pH dependent manner, reaching almost completion, while PU showed no detectable release. Overall, PMMA films blended with ITSCS present favourable characteristics for biomedical coating applications.

\section{Introduction}

With the recent developments in polymer science, the manufacturing of films as vehicles for innovative drug delivery systems is gaining increasing research interest. In the process of generating novel artificial advanced materials, the verified patterns and ways existing in nature serve as a source of inspiration. One of nature's structures that has been investigated the most is the honeycomb, fabricated by bees and organized into cells, which presents outstanding characteristics such as structural stability, high mechanical strength and large surface area. ${ }^{\mathbf{1 - 4}}$ Typically in the lab, ordered porous polymer films can be formed by spin coating or drop casting a polymer solution, which undergoes phase separation upon solvent evaporation. This could be due to a chemically heterogeneous solute (e.g. another polymer), convection (uneven evaporation flows) or breath figures

\footnotetext{
${ }^{a}$ Strathclyde Institute of Pharmacy and Biomedical Sciences (SIPBS), University of Strathclyde, 161 Cathedral Street, Glasgow, G4 ORE, UK. E-mail: D.Lamprou@kent. ac.uk; Tel: +44 (o) 1634883927

${ }^{b}$ NCSR 'Demokritos', Institute of Biosciences and Applications, Athens, Greece. E-mail: sagnou@bio.demokritos.gr

${ }^{c}$ Medway School of Pharmacy, University of Kent, Medway Campus, Anson Building, Central Avenue, Chatham Maritime, Chatham, Kent, ME4 4TB, UK

$\dagger$ Electronic supplementary information (ESI) available. See DOI: 10.1039/c6ra28163j

\$ Equal contribution.
}

(water templating). ${ }^{5}$ The extended templating method of breath figure (BF) has been used to create highly ordered honeycomb structured films containing arrays of pores important for many applications ${ }^{6}$ including catalysts, ${ }^{7}$ antireflective coatings, ${ }^{8}$ templates for inorganic growth masks, ${ }^{9}$ membranes, ${ }^{\mathbf{1 0}}$ cell culture substrates, ${ }^{11}$ tissue engineering and drug delivery ${ }^{\mathbf{1 2}}$ and coatings for medical devices. ${ }^{13}$ This latter application aims to improve the surface characteristics of medical devices, which are strongly dependent on their roughness, hydrophobicity, porosity, and chemical composition. ${ }^{\mathbf{1 4}}$ These properties have been shown to influence protein and bacterial absorption among other undesirable reactions such as inflammation, fibrosis, thrombosis, infection, ${ }^{\mathbf{1 5}}$ and to have a direct impact on safety enhancement of the implanted devices.

Bacterial infection is a serious complication of implanted biomaterials. In 2011, prosthetic infections occurred in 1.3$1.6 \%$ of all knee and hip joint replacement surgeries. ${ }^{16}$ With a view to eradicate the infections associated with film formation, some of the medical devices already in use incorporate a coated surface that is also able to release antimicrobial substances. ${ }^{17-19}$ Local release of the antimicrobial agent into a specific area has shown high effectiveness in the prevention of bacterial adhesion and the formation of microbial films. Therefore, there is an increasing interest in developing new biomedical coatings that can resist bacterial adhesion for tissue engineering. ${ }^{20}$ Moreover, there is growing focus on 


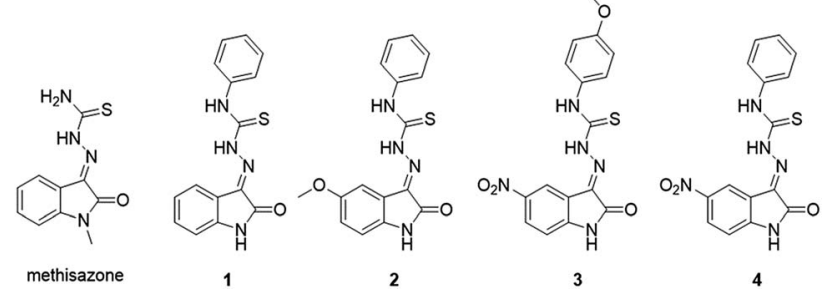

Fig. 1 Structure of methisazone and the tested thiosemicarbazone derivatives $1,2,3$, and 4 .

incorporating antibacterial drugs into biomedical coatings for targeted drug delivery. ${ }^{21}$

The heterocyclic compound $1 H$-indole-2,3-dione, commonly known as isatin is an outstanding building block in organic and medicinal chemistry approaches. Thiosemicarbazone derivatives of isatins (ITSCs) demonstrate a variety of biological activity, including antiviral, antibacterial, anticancer, anticonvulsant and antidepressant activity. ${ }^{22,23} \mathrm{~N}$-Methylisatin- $\beta$-thiosemicarbazone (methisazone) has been studied extensively for their pox-viruses replication inhibition $^{24}$ whereas isatin derivatives also have antifungal and anti-mycotoxin activities. ${ }^{25}$ Addition of ITSCs in poly(methyl methacrylate, PMMA) and polyurethane (PU) solutions was first attempted by our group ${ }^{26}$ in the effort to modify the polymer surface characteristics and alter its biological properties. It was shown that the addition of ITSC to PMMA dissolved in tetrahydrofuran solvent and spin-coated on to a silica wafer promoted the formation of films that displayed honeycomb structures that were highly hydrophobic; this was not observed for PU films. The present study aims to investigate further the influence of the presence of four different ITSCs (1-4, Fig. 1) on polymer film surface characteristics. ITSC $\mathbf{1}$ (K) has been shown to have significant antifungal activity, ${ }^{27}$ antiherpetic activity, ${ }^{28}$ antileishmanial activity, ${ }^{29}$ and antibacterial activity against antibiotic-resistant gram-positive bacterial strains. ${ }^{30}$ ITSC 2 (M) has been shown $^{28}$ to have significant antiherpetic activity whereas isatin derivatives $\mathbf{3}(\mathrm{N})$ and $\mathbf{4}(\mathrm{NM})$ have not been studied in the literature previously.

PMMA and PU films were produced via spin coating in the presence or absence of the four ITSCs and the surface morphology, surface energy and film hydrophobicity were investigated at various concentrations of isatin derivatives. Moreover, dissolution studies were performed to evaluate the drug-releasing ability of the PMMA-ITSC or PU-ITSC blended films.

\section{Experimental}

\section{Materials}

Poly(methyl methacrylate) (PMMA; MW $94.6 \mathrm{~kg} \mathrm{~mol}^{-1}$ ) was purchased from Acros Organics. Polyurethane (PU; MW $88.1 \mathrm{~kg}$ $\mathrm{mol}^{-1}$ ) was purchased from Fluka. Tetrahydrofuran (THF; $>99.9 \%$ ), ethylene glycol (EG; >99.8\%), diiodomethane (DIM; $>99 \%)$, monosodium phosphate $\left(\mathrm{NaH}_{2} \mathrm{PO}_{4}\right)$, sodium hydroxide and sodium chloride were purchased from Sigma and used without further purification. Deionised water (DW) of HPLC grade $(18.2 \mathrm{M} \Omega \mathrm{cm})$ was also used.

\section{Synthesis of isatin derivatives}

The thiosemicarbazones 1-3 were prepared by combining equimolar amounts of the commercially available substituted isatins $(3.5 \mathrm{mmol})$ and thiosemicarbazide $(3.5 \mathrm{mmol})$ dissolved in ethanol followed by the addition of a few drops (100-200 $\mu \mathrm{L})$ of glacial acetic acid to initiate the reaction. The mixture was refluxed overnight and the corresponding thiosemicarbazonederivative precipitated during the course of the reaction. All final compounds were recrystallised from DMSO with a small amount of water.

(E)-2-(2-Oxoindolin-3-ylidene)- $N$-phenylhydrazinecarbothioamide (1). This was synthesised according to the general procedure by reacting isatin with 4-phenyl-3-thiosemicarbazide. Yield $=81 \% .{ }^{1} \mathrm{H}$ NMR $\left(500 \mathrm{MHz}\right.$, DMSO- $\left.d_{6}\right) \delta 12.79(\mathrm{~s}, 1 \mathrm{H}), 11.26(\mathrm{~s}$, $1 \mathrm{H}), 10.82(\mathrm{~s}, 1 \mathrm{H}), 7.78(\mathrm{~d}, J=7.5 \mathrm{~Hz}, 1 \mathrm{H}), 7.61(\mathrm{~d}, J=8.1 \mathrm{~Hz}, 2 \mathrm{H})$, $7.43(\mathrm{t}, J=7.6 \mathrm{~Hz}, 2 \mathrm{H}), 7.37(\mathrm{t}, J=7.7 \mathrm{~Hz}, 1 \mathrm{H}), 7.28(\mathrm{t}, J=7.3 \mathrm{~Hz}$, $1 \mathrm{H}), 7.11(\mathrm{t}, J=7.5 \mathrm{~Hz}, 1 \mathrm{H}), 6.95(\mathrm{~d}, J=7.8 \mathrm{~Hz}, 1 \mathrm{H}) ;{ }^{13} \mathrm{C} \mathrm{NMR}$ $\left(125.5 \mathrm{MHz}, \mathrm{DMSO}-d_{6}\right) \delta 176.37,162.72,142.51,138.47,132.31$, 131.46, 128.40, 126.12, 125.70, 122.38, 121.41, 119.93, 111.11, 39.52; ESI-MS $(\mathrm{m} / \mathrm{z})[\mathrm{M}+\mathrm{H}]^{+}$calculated for $\left[\mathrm{C}_{15} \mathrm{H}_{13} \mathrm{~N}_{4} \mathrm{OS}^{+}\right] 297.08$ found: 297.15, HPLC analysis: peak area $=99.827 \%$, mobile phase A: aq. $\mathrm{CH}_{3} \mathrm{COONH}_{4} 10 \mathrm{mM}, \mathrm{pH}=3.9$ with formic acid; mobile phase $\mathrm{B}: \mathrm{MeOH}$; detected at $255 \mathrm{~nm}$.

(E)-2-(5-Methoxy-2-oxoindolin-3-ylidene)- $N$-phenylhydrazinecarbothioamide (2). This was synthesised according to the general procedure by reacting 5-methoxyisatin with 4-phenyl-3thiosemicarbazide. Yield $=78 \% .{ }^{1} \mathrm{H}$ NMR (500 MHz, DMSO- $d_{6}$ ) $\delta 12.79(\mathrm{~s}, 1 \mathrm{H}), 11.07(\mathrm{~s}, 1 \mathrm{H}), 10.81(\mathrm{~s}, 1 \mathrm{H}), 7.59(\mathrm{~d}, J=7.9 \mathrm{~Hz}$, $2 \mathrm{H}), 7.47-7.39(\mathrm{~m}, 3 \mathrm{H}), 7.29(\mathrm{t}, J=7.3 \mathrm{~Hz}, 1 \mathrm{H}), 6.96(\mathrm{dd}, J=8.5$, $2.2 \mathrm{~Hz}, 1 \mathrm{H}), 6.86(\mathrm{~d}, J=8.5 \mathrm{~Hz}, 1 \mathrm{H}), 3.77(\mathrm{~s}, 3 \mathrm{H}) ;{ }^{13} \mathrm{C}$ NMR $(125.5$ MHz, DMSO- $\left.d_{6}\right) \delta 176.43,162.83,155.34,138.56,136.21,132.55$, 128.44, 126.23, 125.92, 120.73, 117.51, 111.85, 106.65, 55.65; ESI-MS $(m / z)[\mathrm{M}+\mathrm{H}]^{+}$calculated for $\left[\mathrm{C}_{16} \mathrm{H}_{15} \mathrm{~N}_{4} \mathrm{O}_{2} \mathrm{~S}^{+}\right] 327.09$ found: 327.20 , HPLC analysis: peak area $=99.665 \%$, mobile phase A: aq. $\mathrm{CH}_{3} \mathrm{COONH}_{4} 10 \mathrm{mM}, \mathrm{pH}=3.9$ with formic acid; mobile phase B: $\mathrm{MeOH}$; detected at $255 \mathrm{~nm}$.

(E)-N-(4-Methoxyphenyl)-2-(5-nitro-2-oxoindolin-3-ylidene) hydrazinecarbothioamide (3). This was synthesised according to the general procedure by reacting 5 -nitroisatin with $4-(p$ methoxy)phenyl-3-thiosemicarbazide. Yield $=85 \%$. ${ }^{1} \mathrm{H}$ NMR $\left(500 \mathrm{MHz}, \mathrm{DMSO}-d_{6}\right) \delta 12.51(\mathrm{~s}, 1 \mathrm{H}), 11.85(\mathrm{~s}, 1 \mathrm{H}), 11.01(\mathrm{~s}$, $1 \mathrm{H}), 8.70(\mathrm{~s}, 1 \mathrm{H}), 8.29(\mathrm{~d}, J=8.7 \mathrm{~Hz}, 1 \mathrm{H}), 7.45(\mathrm{~d}, J=8.6 \mathrm{~Hz}$, $2 \mathrm{H}), 7.14(\mathrm{~d}, J=8.7 \mathrm{~Hz}, 1 \mathrm{H}), 7.00(\mathrm{~d}, J=8.5 \mathrm{~Hz}, 2 \mathrm{H}), 3.79(\mathrm{~s}$, $3 \mathrm{H}) ;{ }^{13} \mathrm{C}$ NMR $\left(125.5 \mathrm{MHz}\right.$, DMSO- $\left.d_{6}\right) \delta 176.75,163.04,157.60$, 147.40, 142.89, 131.14, 130.11, 127.47, 127.12, 121.04, 116.78, 113.69, 111.33, 55.32; ESI-MS $(\mathrm{m} / \mathrm{z})[\mathrm{M}+\mathrm{H}]^{+}$calculated for $\left[\mathrm{C}_{16} \mathrm{H}_{14} \mathrm{~N}_{5} \mathrm{O}_{4} \mathrm{~S}^{+}\right] 372.08$ found: 372.00 , HPLC analysis: peak area $=97.646 \%$, mobile phase A: aq. $\mathrm{CH}_{3} \mathrm{COONH}_{4} 10 \mathrm{mM}$, pH $=3.9$ with formic acid; mobile phase $\mathrm{B}: \mathrm{MeOH}$; detected at $255 \mathrm{~nm}$.

Compound (4) was synthesised according to literature ${ }^{28}$ and used as positive control. Air sensitive chemical synthesis was performed in dry and inert conditions under a nitrogen atmosphere. All reactions were routinely checked by thin-layer chromatography (TLC) on silica gel Merck 60 F254 and compounds were purified by column chromatography on silica 
gel using the appropriate solvent systems or by preparative high-performance liquid chromatography (HPLC). The purity of the compounds tested biologically was determined by an analytical HPLC method and was found to be greater than or equal to $95 \%$. The purity was determined automatically by the parameters of the MS analysis performed on a HPLC Shimadzu 2010EV (Column: Merck Purospher RP-C8, $250 \times 4.6 \mathrm{~mm}, 5 \mu \mathrm{m}$ particle size), equipped with a SPD-20A UV/Vis detector. Characterisation of target compounds was established by a combination of ESI-MS and NMR techniques. ${ }^{1} \mathrm{H}$ and ${ }^{13} \mathrm{C}$ NMR spectra were recorded on a Bruker Advance DRX $500 \mathrm{MHz}$ spectrometer. Chemical shifts are presented in ppm $(\delta)$ with internal TMS standard. Original ${ }^{1} \mathrm{H}$ and ${ }^{13} \mathrm{C}$ NMR spectra are presented in the ESI section (Fig. S1-S4). $\dagger$ MS were obtained by the mass detector of the HPLC Shimadzu 2010EV.

\section{Spin coating}

The spin coating method was employed to obtain thin films of uniform thickness on silica wafer (SW) substrates. PMMA and PU polymers were used as purchased with no further treatment and dissolved in THF to obtain a final solution of $2 \% \mathrm{w} / \mathrm{v}$. Solutions were left overnight to ensure complete dissolution. Isatin derivatives were dissolved in THF at $10 \mathrm{mg} \mathrm{mL}$. Aliquots were added to the polymer solution to provide final preparations at various isatin concentrations: 10, 100 and 500 $\mu \mathrm{M}$. SW was cut into $100-200 \mathrm{~mm}^{2}$ square pieces and carefully cleaned with DW, followed by $70 \% \mathrm{v} / \mathrm{v}$ ethanol and with THF. The solutions were manually applied with a syringe to the substrate, which was then spun to spread the liquid with a Laurell WS-400-6NPP spin coater at $2000 \mathrm{rpm}$ for $30 \mathrm{~s}$ at ambient temperature $\left(20-25{ }^{\circ} \mathrm{C}\right)$ and ambient humidity (20$30 \% \mathrm{RH}$ ) measured with an Exo Terra digital hygrometer. For each solution prepared, experiments were repeated at least in triplicate.

\section{Atomic force microscopy}

Atomic force microscopy (AFM) is an effective tool for the characterisation of polymer films providing information about the morphology of the compound as well as nanoscale data of different physical properties of the polymer. From analysis of height maps of the polymer films, the pore density (number of pores in an area) and roughness of the films were calculated.

AFM images were acquired using a Bruker Multimode 8 atomic force microscope with a Nanoscope $\mathrm{V}$ controller in ambient conditions. ScanAsyst Air probes (Bruker) with Vshaped silicon nitride cantilevers with spring constants in the range $0.25-0.4 \mathrm{~N} \mathrm{~m}^{-1}$ were used. Samples were studied using a peak force quantitative nanomechanical mapping (PF-QNM) mode in air at a resolution of 512 samples per line and a scan rate of $1.0 \mathrm{~Hz}$. Roughness $\left(R_{\mathrm{a}}\right)$ was calculated using Nanoscope Analysis 1.6 software on five $5 \times 5 \mu \mathrm{m}$ images.

\section{Contact angle goniometry}

Contact angle goniometry (CAG) is used to determine the hydrophobicity/hydrophilicity of a surface. Drops of DW, EG and DIM were placed onto surfaces, giving contact angles at the three-phase interface between the solid, liquid and gas phases.

The analysis of these contact angles allowed the calculation of surface energies. The surface energy $\left(\gamma_{\mathrm{s}}\right)$ and surface energy components values for each sample were determined by the measurement of the advancing contact angles $\left(\theta_{\mathrm{A}}\right)$ of three different solvents on the surfaces DW $\left(18.2 \mathrm{M} \Omega \mathrm{cm}, \gamma_{\mathrm{L}} 72.8 \mathrm{mN}\right.$ $\mathrm{m}^{-1}$ at $\left.20{ }^{\circ} \mathrm{C}\right)$, EG $\left(\gamma_{\mathrm{L}} 48.0 \mathrm{mN} \mathrm{m}^{-1}\right.$ at $\left.20{ }^{\circ} \mathrm{C}\right)$ and DIM $\left(\gamma_{\mathrm{L}} 50.8\right.$ $\mathrm{mN} \mathrm{m}^{-1}$ at $20^{\circ} \mathrm{C}$ ) (surface tension $\gamma_{\mathrm{L}}$ values from Lamprou et $a l .{ }^{31}$ ). The contact angles of the spin-coated surfaces were measured with a Krüss DSA30B contact angle goniometer, using the sessile drop method with the Krüss Advance software. Advancing contact angles $\left(\theta_{\mathrm{A}}\right)$ were calculated from the left and right side of each drop 5-10 s after the placement of the drop on the surface. Finally, the surface energies $\left(\gamma_{\mathrm{s}}\right)$ were obtained by calculating the mean contact angles using the Good and Oss 3-liquid formula [eqn (1)] via an in-house Visual Basic program. ${ }^{31}$ The measurement was repeated for a minimum of three samples for each polymer film, measuring 3 to 4 drops per sample $(n=9-12)$.

$$
\frac{\sigma L(\cos \theta+1)}{\sqrt[2]{\sigma_{\mathrm{L}}^{\mathrm{D}}}}=\frac{\sqrt{\sigma_{\mathrm{S}}^{\mathrm{P}}} \sqrt{\sigma_{\mathrm{L}}^{\mathrm{P}}}}{\sqrt{\sigma_{\mathrm{L}}^{\mathrm{D}}}}+\sqrt{\sigma_{\mathrm{S}}^{\mathrm{D}}}
$$

\section{In vitro release studies}

Release studies are a suitable technique to determine the dissolution rate of a compound in a specific aqueous media, using small sample weights.

The release of compound $2(500 \mu \mathrm{M})$ from a PMMA film was carried out at room temperature using a SiriusT3 instrument. To determine the best $\mathrm{pH}$ range for the release of the drug, a standard dissolution test was carried out by immersing the polymer film into $20 \mathrm{~mL}$ of phosphate buffer adjusted to a starting pH 2.0. The release of 2 was directly measured by multi-wavelength UV absorption spectroscopy using an in situ fibre-optic UV probe. The data were recorded for $24 \mathrm{~h}$ starting at $\mathrm{pH} 2.0$ and increasing the $\mathrm{pH}$ every $6 \mathrm{~h}$ by the addition of $\mathrm{KOH}$ via a capillary to determine the optimum $\mathrm{pH}$ for the release. At the end of the study, the dissolution at different $\mathrm{pH}$ of $2.04,3.85,5.37$ and 7.26 were recorded, showing the highest release profile in the $\mathrm{pH}$ range 5.37 to 7.26. Therefore, further analysis was performed by repeating the experiment using $\mathrm{pH}$ 6.46. Data was recorded for $24 \mathrm{~h}$ showing that at $\mathrm{pH} 6.46 \pm 0.02$ the drug was released in a continuous manner through time. During the experiment the solution was continuously stirred at a constant rate. Absorption data were converted to absolute sample weight $(\mu \mathrm{g})$ and plotted against time (min).

\section{Statistical analysis}

Significances for energy surface were calculated through $t$-test for each pair of samples within each concentration. Significances for roughness and pore density (pores in an area), were found with two-way ANOVA test for each factor, i.e., polymer, isatin derivative concentration and isatin derivative structure. Significance tests were carried out with Minitab 17 with a significance level of 0.05 . 


\section{Results and discussion}

\section{Contact angle goniometry}

Advancing contact angles $\left(\theta_{\mathrm{A}}\right)$ of DW, DIM and EG were calculated on PMMA or PU surfaces with and without isatin derivatives. The values are displayed in Tables 1-3 for different ITSC concentrations, namely 10, 100 and $500 \mu \mathrm{M}$. Upon addition of ITSC the water contact angle values increased in both PMMA and PU films, from a minimum of $83.9^{\circ} \pm 4.5$ for PMMA and $85.3^{\circ} \pm 0.2$ for PU to a maximum of $129.3^{\circ} \pm 2.6$ and $102.1^{\circ} \pm$ 1.4, respectively. The effect of ITSCs addition on advancing contact angles of EG and DIM follows a similar trend. This is in agreement with Mallinson et al., ${ }^{26}$ who also observed an increase in hydrophobicity caused by the addition of isatin thiosemicarbazones to the polymer. As previously observed, ${ }^{28}$ the effect of ITSC addition was much more dramatic in the case of PMMA film formation, leading to highly hydrophobic surfaces, compared to the PU counterparts.

It can be clearly seen from the Tables 1-3 that the effect of ITSCs on $\theta_{\mathrm{A}}$ is concentration dependent. A statistically significant surface hydrophobicity increase $(p<0.05)$ was observed for concentrations of 100 and $500 \mu \mathrm{M}$ compared to baseline, while no statistical significant change in $\theta_{\mathrm{A}}$ was observed for the low ITSC concentration $10 \mu \mathrm{M}$. These results indicate the direct and active participation of ITSC in the BF phenomenon. The fact that the effect of the $100 \mu \mathrm{M}$ and $500 \mu \mathrm{M}$ concentration is within

Table 1 Advancing contact angles $\left(\theta_{\mathrm{A}}\right)$ for DW, EG and DIM for PMMA and PU blended with ITSCs $(10 \mu \mathrm{M})$

\begin{tabular}{lllll}
\multicolumn{5}{l}{ Advancing contact angles $\left(\theta_{\mathrm{A}}\right) /$} \\
\hline Polymer & ITSC & \multicolumn{1}{l}{ DW } & \multicolumn{1}{l}{ EG } & \multicolumn{1}{l}{ DIM } \\
\hline SW & None & $62.1 \pm 6.7$ & $44.8 \pm 7.6$ & $54.0 \pm 3.4$ \\
PMMA & None & $83.9 \pm 4.5$ & $60.5 \pm 4.7$ & $40.2 \pm 0.5$ \\
PU & None & $85.3 \pm 0.2$ & $61.9 \pm 4.0$ & $37.3 \pm 4.8$ \\
PMMA & $\mathbf{1}$ & $93.4 \pm 2.7$ & $72.7 \pm 3.2$ & $39.7 \pm 1.8$ \\
PMMA & $\mathbf{2}$ & $91.8 \pm 1.9$ & $68.9 \pm 5.9$ & $35.8 \pm 1.8$ \\
PMMA & $\mathbf{3}$ & $90.5 \pm 4.3$ & $70.7 \pm 2.2$ & $38.6 \pm 2.7$ \\
PMMA & $\mathbf{4}$ & $118.8 \pm 0.7$ & $96.5 \pm 2.7$ & $73.0 \pm 5.4$ \\
PU & $\mathbf{1}$ & $88.8 \pm 3.3$ & $68.4 \pm 0.7$ & $31.6 \pm 1.9$ \\
PU & $\mathbf{2}$ & $92.1 \pm 1.8$ & $71.4 \pm 1.5$ & $32.1 \pm 1.7$ \\
PU & $\mathbf{3}$ & $84.4 \pm 1.1$ & $65.4 \pm 2.4$ & $30.6 \pm 2.8$ \\
PU & $\mathbf{4}$ & $88.8 \pm 1.8$ & $63.9 \pm 2.2$ & $34.9 \pm 1.6$
\end{tabular}

Table 2 Advancing contact angles $\left(\theta_{\mathrm{A}}\right)$ for DW, EG and DIM for PMMA and PU blended with ITSCs $(100 \mu \mathrm{M})$

\begin{tabular}{llrrl}
\multicolumn{5}{l}{ Advancing contact angles $\left(\theta_{\mathrm{A}}\right) /{ }^{\circ}$} \\
\hline Polymer & ITSC & \multicolumn{1}{c}{ DW } & \multicolumn{1}{c}{ EG } & \multicolumn{1}{l}{ DIM } \\
\hline PMMA & $\mathbf{1}$ & $129.3 \pm 2.6$ & $100 \pm 3.6$ & $37.9 \pm 3.6$ \\
PMMA & $\mathbf{2}$ & $123.5 \pm 3.7$ & $94.5 \pm 6.3$ & $41.2 \pm 0.5$ \\
PMMA & $\mathbf{3}$ & $123.6 \pm 2.7$ & $100.0 \pm 2.0$ & $36.7 \pm 0.9$ \\
PMMA & $\mathbf{4}$ & $119.6 \pm 0.6$ & $91.4 \pm 5.8$ & $41.7 \pm 1.8$ \\
PU & $\mathbf{1}$ & $101.7 \pm 0.5$ & $72.8 \pm 2.8$ & $32.2 \pm 0.1$ \\
PU & $\mathbf{2}$ & $100.6 \pm 0.8$ & $72.1 \pm 0.2$ & $32.0 \pm 0.2$ \\
PU & $\mathbf{3}$ & $97.4 \pm 3.2$ & $72.9 \pm 2.2$ & $32.0 \pm 0.3$ \\
PU & $\mathbf{4}$ & $101.5 \pm 1.4$ & $72.7 \pm 3.9$ & $32.5 \pm 1.3$
\end{tabular}

Table 3 Advancing contact angles $\left(\theta_{\mathrm{A}}\right)$ for DW, EG and DIM for PMMA and PU blended with ITSCS $(500 \mu \mathrm{M})$

\begin{tabular}{llrrl}
\hline \multicolumn{5}{l}{ Advancing contact angles $\left(\theta_{\mathrm{A}}\right) /^{\circ}$} \\
\hline Polymer & ITSC & \multicolumn{1}{l}{ DW } & \multicolumn{1}{c}{ EG } & \multicolumn{1}{l}{ DIM } \\
\hline PMMA & $\mathbf{1}$ & $123.6 \pm 2.2$ & $100.3 \pm 1.2$ & $39.6 \pm 1.9$ \\
PMMA & $\mathbf{2}$ & $119.8 \pm 5.0$ & $92.6 \pm 4.2$ & $37.2 \pm 2.8$ \\
PMMA & $\mathbf{3}$ & $121.9 \pm 1.2$ & $93.8 \pm 6.6$ & $33.6 \pm 0.5$ \\
PMMA & $\mathbf{4}$ & $128.0 \pm 1.3$ & $100.5 \pm 3.3$ & $38.1 \pm 0.6$ \\
PU & $\mathbf{1}$ & $102.1 \pm 1.4$ & $72.6 \pm 1.7$ & $30.2 \pm 1.5$ \\
PU & $\mathbf{2}$ & $102.1 \pm 1.8$ & $72.2 \pm 0.1$ & $21.3 \pm 1.5$ \\
PU & $\mathbf{3}$ & $101.1 \pm 3.1$ & $69.5 \pm 5.1$ & $30.2 \pm 1.2$ \\
PU & $\mathbf{4}$ & $101.1 \pm 1.9$ & $73.4 \pm 0.3$ & $34.2 \pm 0.4$
\end{tabular}

the same range suggests that the effect reaches a plateau. It is worth mentioning that this concentration-dependent behaviour resembles the effect on hydrophobicity observed during copolymerisation processes, by either changing the concentration or the type of the film polymers, ${ }^{29,30}$ a fact that indicates the direct and active participation of ITSC in the BF phenomenon.

Furthermore, it is notable that even though PMMA and PU are hydrophilic polymers with an intrinsic contact angle lower than $90^{\circ}$, the films obtained in the presence of 100 and $500 \mu \mathrm{M}$ of ITSCs exhibit angles around or above $100^{\circ}$, with the PMMA films reaching up to $129^{\circ}$ in the presence of ITSC 1 . Changes in the wettability of the surfaces have been presented in the literature associated with different mechanisms of preparation, the influence of air plasma on the surfaces, or ultraviolet ozone treatment of the surfaces. ${ }^{32-36}$ In our case, the observed change from hydrophilic to hydrophobic can only be due to the presence of the extended aromatic system of the ITSCs and the way it interacts with the polymer or even self-assembles during the film-preparation process. This is the first to our knowledge case in the literature where a change in the wettability of the surface occurs by the simple addition of a small organic molecule in the THF-polymer system.

The surface energy calculations showed high similarity between the PMMA and PU films. Overall, the surface energy in PMMA

Table 4 Surface energy components $\left(\gamma_{S}\right)$ of spin coated surfaces calculated from CAG measurements for PMMA and PU polymer film containing ITSCs $(10 \mu \mathrm{M})$

\begin{tabular}{|c|c|c|c|c|c|c|}
\hline \multicolumn{2}{|l|}{ Surface } & \multicolumn{4}{|c|}{ Surface energy $/ \mathrm{mJ} \mathrm{m}^{-2}$} & \multirow{2}{*}{$\begin{array}{l}\text { Roughness }\left(R_{\mathrm{a}}\right) \\
\text { by } \mathrm{AFM} / \mathrm{nm}\end{array}$} \\
\hline Polymer & ITSC & $\gamma_{\mathrm{s}}{ }^{-}$ & $\gamma_{\mathrm{s}}^{+}$ & $\gamma_{\mathrm{S}}^{\mathrm{LW}}$ & $\gamma_{\mathrm{s}}$ & \\
\hline SW & None & 22.77 & 0.33 & 32.00 & 37.49 & $1.09 \pm 0.10$ \\
\hline PMMA & None & 5.54 & 0.04 & 39.50 & 40.43 & $20.33 \pm 5.51$ \\
\hline PU & None & 4.88 & 0.10 & 40.94 & 42.36 & $17.77 \pm 2.68$ \\
\hline PMMA & 1 & 2.87 & 0.57 & 39.78 & 42.33 & $31.73 \pm 4.03$ \\
\hline PMMA & 2 & 2.74 & 0.41 & 41.65 & 43.78 & $17.68 \pm 7.89$ \\
\hline PMMA & 3 & 4.06 & 0.54 & 40.30 & 43.27 & $26.25 \pm 4.71$ \\
\hline PMMA & 4 & 0.00 & 0.26 & 21.21 & 21.22 & $23.37 \pm 0.99$ \\
\hline PU & 1 & 4.30 & 0.66 & 43.54 & 46.92 & $30.77 \pm 5.45$ \\
\hline PU & 2 & 3.13 & 0.82 & 43.32 & 46.53 & $27.35 \pm 3.65$ \\
\hline PU & 3 & 6.48 & 0.59 & 43.98 & 47.90 & $29.45 \pm 5.23$ \\
\hline PU & 4 & 3.15 & 0.17 & 42.07 & 43.54 & $21.15 \pm 1.91$ \\
\hline
\end{tabular}


Table 5 Surface energy components $\left(\gamma_{\mathrm{S}}\right)$ of spin coated surfaces calculated from CAG measurements for PMMA and PU polymer film containing ITSCS $(100 \mu \mathrm{M})$

\begin{tabular}{|c|c|c|c|c|c|c|}
\hline \multicolumn{2}{|l|}{ Surface } & \multicolumn{4}{|c|}{ Surface energy $/ \mathrm{mJ} \mathrm{m}^{-2}$} & \multirow{2}{*}{$\begin{array}{l}\text { Roughness }\left(R_{\mathrm{a}}\right) \\
\text { by } \mathrm{AFM} / \mathrm{nm}\end{array}$} \\
\hline Polymer & ITSC & $\gamma_{\mathrm{s}}{ }^{-}$ & $\gamma_{\mathrm{s}}^{+}$ & $\gamma_{\mathrm{S}}^{\mathrm{LW}}$ & $\gamma_{\mathrm{s}}$ & \\
\hline PMMA & 1 & 2.03 & 3.32 & 40.64 & 45.84 & $46.04 \pm 2.15$ \\
\hline PMMA & 2 & 1.16 & 2.14 & 39.01 & 42.17 & $31.47 \pm 2.08$ \\
\hline PMMA & 3 & 0.50 & 4.02 & 41.23 & 44.07 & $40.50 \pm 3.47$ \\
\hline PMMA & 4 & 0.62 & 1.72 & 38.73 & 40.80 & $31.76 \pm 1.47$ \\
\hline PU & 1 & 0.14 & 0.5 & 43.28 & 43.82 & $40.26 \pm 4.04$ \\
\hline PU & 2 & 0.24 & 0.48 & 43.38 & 44.06 & $37.53 \pm 4.91$ \\
\hline PU & 3 & 1.09 & 0.73 & 43.36 & 45.13 & $37.85 \pm 2.47$ \\
\hline PU & 4 & 0.26 & 0.32 & 42.73 & 43.30 & $35.74 \pm 3.98$ \\
\hline
\end{tabular}

Table 6 Surface energy components $\left(\gamma_{s}\right)$ of spin surfaces calculated from CAG measurements for PMMA and PU polymer film containing ITSCS $(500 \mu \mathrm{M})$

\begin{tabular}{|c|c|c|c|c|c|c|}
\hline \multicolumn{2}{|l|}{ Surface } & \multicolumn{4}{|c|}{ Surface energy $/ \mathrm{mJ} \mathrm{m}^{-2}$} & \multirow{2}{*}{$\begin{array}{l}\text { Roughness }\left(R_{\mathrm{a}}\right) \\
\text { by AFM/nm }\end{array}$} \\
\hline Polymer & ITSC & $\gamma_{\mathrm{s}}^{-}$ & $\gamma_{\mathrm{s}}^{+}$ & $\gamma_{\mathrm{S}}^{\mathrm{LW}}$ & $\gamma_{\mathrm{s}}$ & \\
\hline PMMA & 1 & 0.45 & 3.78 & 39.79 & 42.41 & $43.97 \pm 1.07$ \\
\hline PMMA & 2 & 0.58 & 2.35 & 40.98 & 43.32 & $37.30 \pm 7.05$ \\
\hline PMMA & 3 & 0.93 & 2.78 & 42.65 & 45.87 & $35.23 \pm 1.92$ \\
\hline PMMA & 4 & 1.49 & 3.58 & 40.53 & 45.15 & $30.45 \pm 0.49$ \\
\hline PU & 1 & 0.08 & 0.53 & 44.13 & 44.54 & $38.23 \pm 3.30$ \\
\hline PU & 2 & 0.05 & 0.78 & 47.40 & 47.79 & $45.33 \pm 2.30$ \\
\hline PU & 3 & 0.05 & 0.29 & 44.15 & 44.39 & $40.55 \pm 2.05$ \\
\hline PU & 4 & 0.27 & 0.52 & 42.43 & 43.18 & $44.35 \pm 0.78$ \\
\hline
\end{tabular}

films was slightly lower than PU, which is in agreement with the values obtained for the water contact angles. This correlation is more clearly revealed at lower ITSC concentrations (Tables 4-6). This behaviour is consistent with the roughness values calculated for each film by AFM (Tables 4-6) as high roughness on polymer surfaces can lead to an increase of water contact angles due to the 'lotus effect'. ${ }^{32}$ The "lotus effect", initially studied by Cassie and Baxter, ${ }^{33}$ takes place when air pockets rest under the drop causing super-hydrophobicity by affecting the apparent contact angle at the boundary between the liquid and the solid surface.

The statistical test one-way and two-way ANOVAs, showed a significant effect of the added ITSCs on the surface roughness. Within the same polymer, the roughness increased when concentration increased from $10 \mu \mathrm{M}$ to $100 \mu \mathrm{M}$ with a less pronounced increase from the $100 \mu \mathrm{M}$ to the $500 \mu \mathrm{M}$ concentration. In the case of PMMA surfaces there is a distinct variability of surface roughness depending on the type of ITSC added while the PU surface roughness seems to be less drastically affected by the nature of the ITSC added. The roughness results agree with the high contact angle measurements obtained and the surface energies calculated providing additional evidence for the effect of the added ITSCs on the polymer film characteristics.

\section{Atomic force microscopy}

AFM images are shown in Fig. 2, 3 and 4 for PMMA and PU films blended together with ITSCs of 10, 100 and $500 \mu \mathrm{M}$. The AFM results show that the presence of ITSCs leads to formation of honeycomb structures and confirms our previous results ${ }^{26}$ where it was shown that the lack of isatin derivative prevents the formation of pores. It is evident in the images that PMMA surfaces present a structured honeycomb arrangement with smaller pore diameter $(280 \pm 20 \mathrm{~nm})$ than the PU films $(647 \pm$ $54 \mathrm{~nm})$.

The mean values and standard deviation of pore density for each surface at 10, 100 and $500 \mu \mathrm{M}$ of each ITSC are shown in Fig. 5. These results agree with the high hydrophobicity of the films, as they show unequal surfaces providing space for air pockets.

As evidenced by the differences found in the surface film characteristics, the behaviour of the surface is affected to some extent by the presence of different isatin derivatives and the variety of concentrations used. The data obtained was subjected to statistical analysis that confirmed an interaction between the polymer nature and the isatin which directly affects the physical properties of the films. From the pore density values in Fig. 5 it is obvious that PMMA produce films of higher porosity. In both films increasing concentrations of ITSCs cause an upward trend in porosity confirming the catalytic effect of ITSCs on pore formation. Apparently, during the BF process, hydrophobic or $\pi-\pi$ stacking interactions cause these molecules to selfassemble enhancing patterned honeycomb structure formation. The results of our previous work indicated that the presence of the amide - $\mathrm{NH}$ group is important in enhancing the $\mathrm{BF}$ phenomenon. It appears plausible that the $-\mathrm{OCH}_{3}$ or $-\mathrm{NO}_{2}$
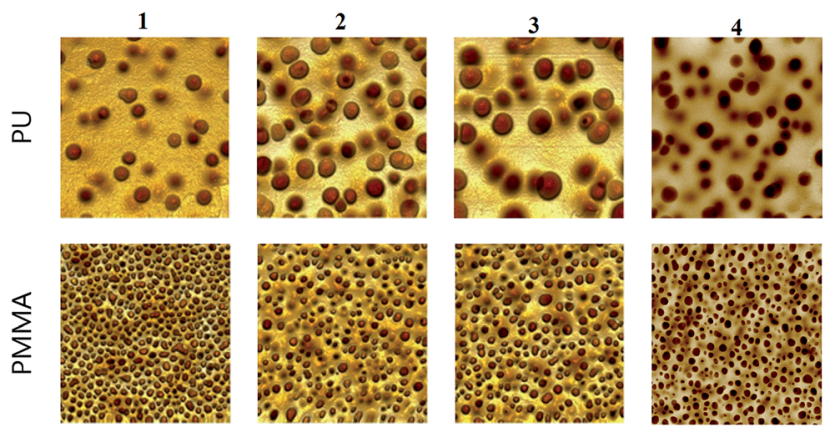

Fig. 2 AFM height images with 3D effect of PMMA and PU with ITSCs $1,2,3$ and 4 at $10 \mu \mathrm{M}$. Images are $5 \times 5 \mu \mathrm{m}$.
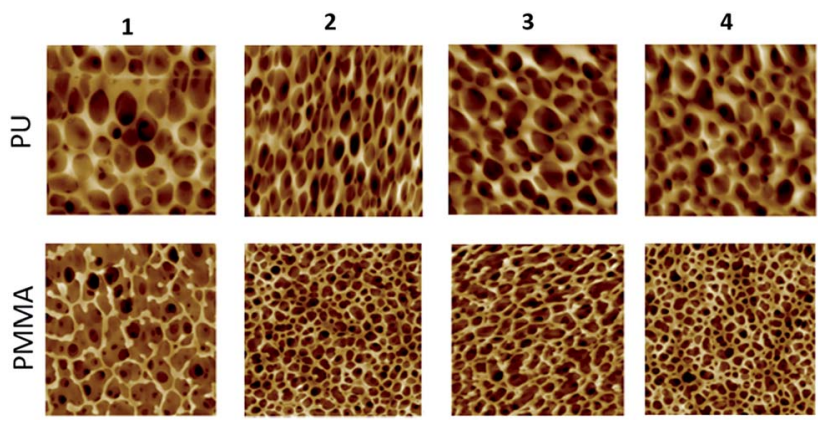

Fig. 3 AFM height images with 3D effect of PMMA and PU with ITSCS $1,2,3$ and 4 at $100 \mu \mathrm{M}$. Images are $5 \times 5 \mu \mathrm{m}$. 

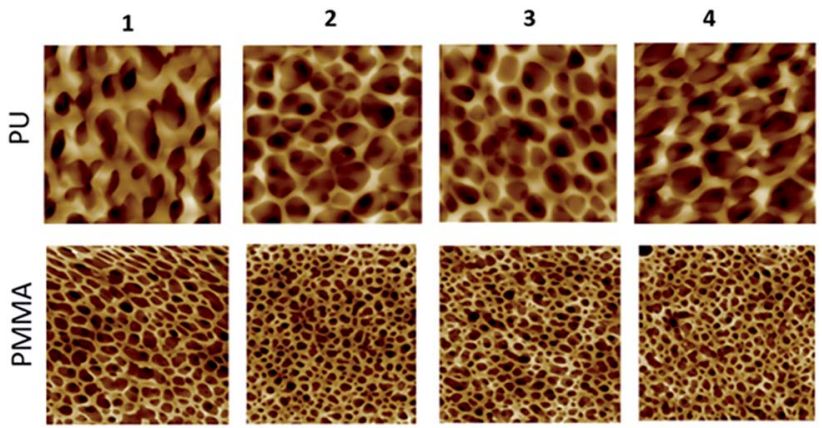

Fig. 4 AFM height images with 3D effect of PMMA and PU with ITSCs $1,2,3$ and 4 at $500 \mu \mathrm{M}$. Images are $5 \times 5 \mu \mathrm{m}$.

(a)

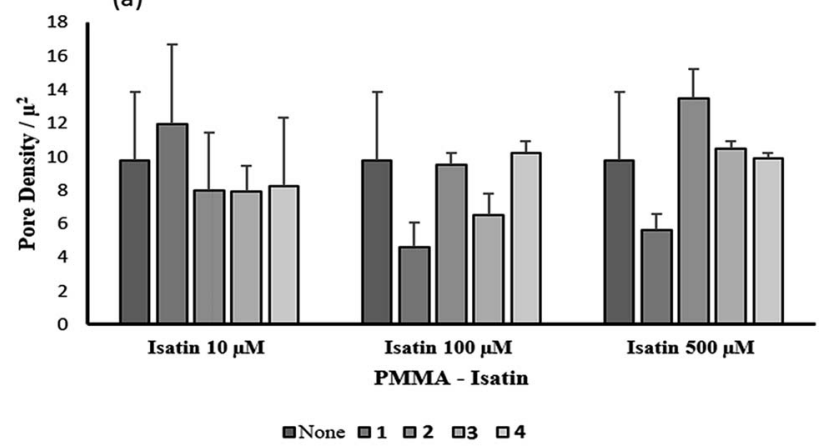

(b)

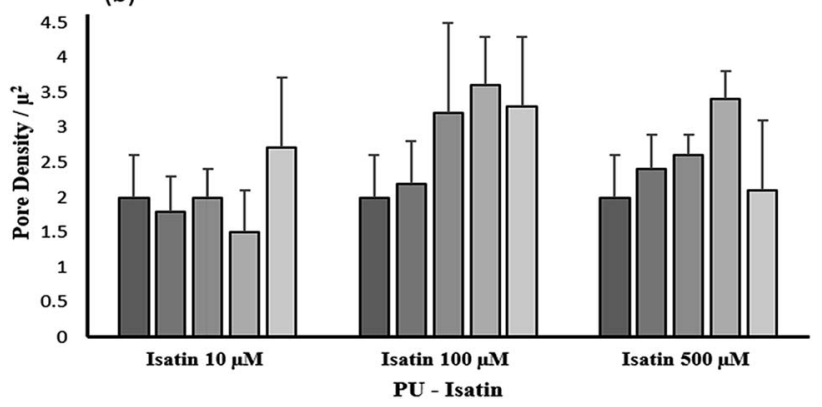

Fig. 5 Pore density calculated for surfaces prepared of PMMA (a) or PU (b), and doped with ITSCs at 10,100 and $500 \mu \mathrm{M}$. A control with no isatin derivatives was also used.

substituent in position 5 of ITSCs 2,3 , and 4 may participate in intermolecular hydrogen bonding with the amide $-\mathrm{NH}$ group further enhancing and stabilizing the molecular networking. Even though, as showed by Bunz, ${ }^{34}$ the parameters which affect the final honeycomb structure are very diverse and the formation of breath figure arrays presents intricate thermodynamic, kinetic and entropic characteristic not completely understood, it is clearly shown in this work that the presence of the ITSCs is a determining factor for honeycomb structure formation.

\section{In vitro release study}

Initially, a drug release investigation was performed using the lowest hydrophobicity surface of the PMMA surface produced, by adding $500 \mu \mathrm{M}$ of ITSC 2 to PMMA in THF. Phosphate buffer was selected as a dissolution medium, being a suitable biorelevant solvent, providing the appropriate conditions to investigate drug release at different $\mathrm{pH}$ values. The maximum amount of ITSC released was measured at pH 7.25 reaching a value of $5 \mu \mathrm{g}$, which correlates well with the quantity of drug assumed to be present at the beginning of the experiment. The SW surface was loaded with $0.4 \mathrm{~mL}$ of solution containing $16 \mu \mathrm{g}$ of ITSC 2, however during the spin coating a great amount of compound is lost due to the high speed applied..$^{6,35}$

Fig. 6 shows a great dependence of drug release on $\mathrm{pH}$ and the dissolution profiles present a discontinuous release as different process over all the $\mathrm{pH}$ areas of analysis in this studies. The average of dissolved drug per sections and the total amount released with their standard deviations can be found in Table 7 . ITSCs are Schiff bases and pH alterations are anticipated to affect the degree of protonation/deprotonation of the molecules. At the low $\mathrm{pH}$ values of the study, it has been suggested that protonation takes place at the oxo group of the isatin fivemembered ring. ${ }^{36}$ The basic character of ITSC 2 may be affected by the methoxy group mesomeric electron-donation effect which can be transferred through conjugation to the imine nitrogen of the five-membered indole ring. Since the increasing $\mathrm{pH}$ sectors seem to accumulate a correspondent increasing amount of ITSCs, the acidic properties of the molecule seem to dominate.

An additional in vitro dissolution study was performed at $\mathrm{pH}$ 6.46 to confirm the release profile of ITSC 2 . Fig. 7 presents the continuous release of drug, with a maximum dissolved mass of $\sim 6 \mu \mathrm{g}, 10 \mathrm{~h}$ after the initiation of the experiment.

The in vitro release studies demonstrate that the ITSC investigated does not remain in the polymer for a prolonged period of time, which could promote antibiotic resistance. Similar polymeric systems with extended release of antibiotics have been found to be problematic as lingering around at low (subminimum inhibitory concentration (MIC)) values, which can be a major issue in terms of promoting antibiotic resistance.

The same study was repeated with PU film though in this case the results did not show any release. Based on this data and the images from the AFM, it may also be suggested that due to the great difference in the pore diameter and pore density, the PU films did not have the optimum features needed such as

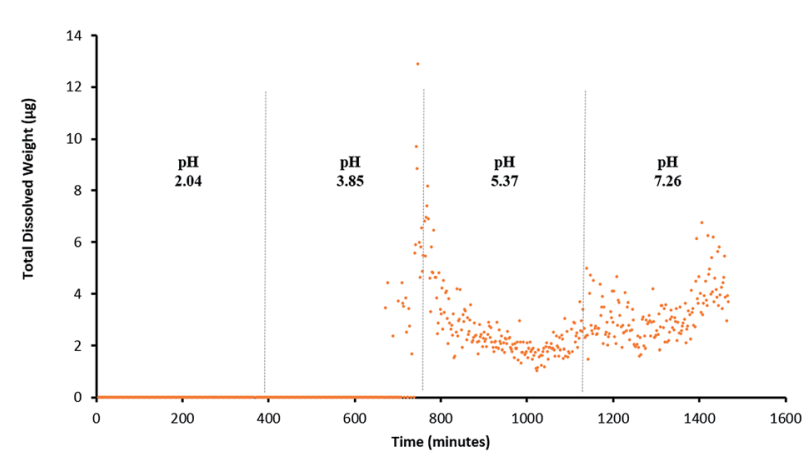

Fig. 6 Amount of ITSC 2 released from 2\% w/v PMMA film over four specific $\mathrm{pH}$ sectors (6 $\mathrm{h}$ each) at room temperature. The initial concentration of ITSC 2 was $500 \mu \mathrm{M}$. 
Table 7 Summary of release of ITSC 2 results from PMMA film performed at $20 \mathrm{~mL}$ volume of phosphate buffer for a period of $24 \mathrm{~h}$ at room temperature. The peak concentration shows the average amount dissolved in sector $4(\mathrm{pH} 7.26)$ reaching the highest value after 1428 minutes

\section{$\mathrm{pH}$ range}

End of sector 1 ( $\mathrm{pH} 2.04)$

End of sector 2 ( $\mathrm{pH} 3.85)$

End of sector 3 (pH 5.37)

End of sector 4 ( $\mathrm{pH} 7.26)$

Peak concentration (time)

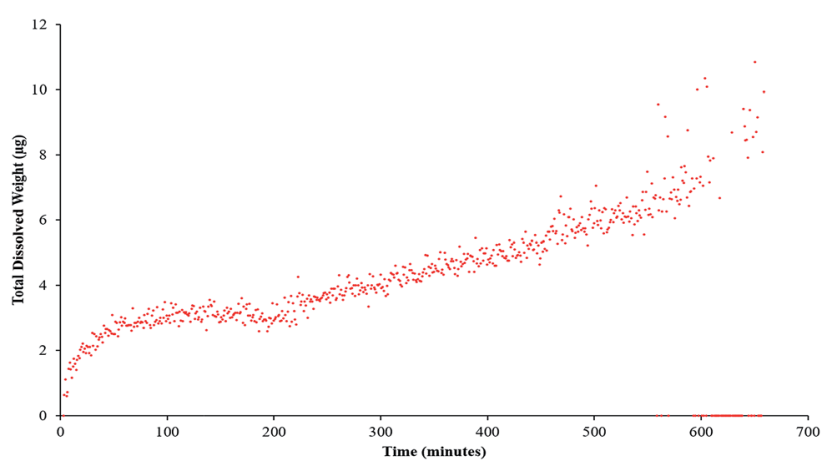

Fig. 7 Amount of ITSC 2 released from $2 \%$ w/v PMMA film over $24 \mathrm{~h}$ at room temperature. The initial concentration of ITSC 2 was $500 \mu \mathrm{M}$.

high density of pores and smaller pore size to increase the surface available for the release of drug, to enable the drug to be released from the surface. Little work has been done in this area, however, the study carried out by Ponnusamy et al., gave some insight of the surface behaviour. ${ }^{37}$ They have determined that films formed by the $\mathrm{BF}$ method appeared to have a higher release profile than non-BF films. In addition, the drug dissolution was completed after 5 days, followed by the degradation of the surface.

\section{Conclusions}

To further our ongoing investigation on the effect of isatin thiosemicarbazones on the surface characteristics of spincoated PMMA and PU polymer films, four different ITSCs were investigated. There was clear indication that both the structure and the concentration of the molecules affect surface characteristics in a different way. All surfaces formed exhibit high hydrophobicity and honeycomb arrangements. Moreover, the concentration dependent manner of influencing hydrophobicity, roughness and porosity provides strong evidence for the direct and determining involvement of the additive ITSCs to the BF effect. The "drug" release studies showed that the ITSCs were released in a pH-dependent way from PMMA films while no release was observed with PU films. Pore size may have an effect on ITSC dissolution, however other characteristics of the polymer film structure may play a role. In conclusion, the addition of ITSC to PMMA films provides a new tool for modifying surface properties and characteristics aiming at their optimisation in view of their potential as novel coatings of biomedical devices. ITSCs constitute one of the very few examples in the literature where small organic molecules affect film surface characteristics and open new ground for development in polymer films.

\section{Acknowledgements}

The authors would like to thank the University of Strathclyde and the EPSRC Centre in Continuous Manufacturing and Crystallisation (CMAC) for access to equipment. The authors would also like to acknowledge the Hellenic Republic and the European Union as part of the European Regional Development Fund, in the context of the OP Competitiveness and Entrepreneurship (OPC II) and the ROP Attica, ROP Macedonia - Thrace, through the implementation of the program KRIPIS-DIAS, Institute of Biosciences \& Applications, NCSR 'Demokritos' for their financial support.

\section{References}

$1 \mathrm{H}$. Human, S. W. Nicolson and V. Dietemann, Naturwissenschaften, 2006, 93, 397.

2 M. Toyoda, K. Sakagami, D. Takahashi and M. Morimoto, Appl. Acoust., 2011, 72, 943.

3 K. Zhang, F. W. Si, H. L. Duan and J. Wang, Acta Biomater., 2010, 6, 2165.

4 J. L. Gould, The Biology of the Honey Bee. Mark L. Winston, Q. Rev. Biol., 1988, 63, 95.

5 P. Escalé, L. Rubatat, L. Billon and M. Save, Eur. Polym. J., 2012, 48, 1001.

6 A. Zhang, H. Bai and L. Li, Chem. Rev., 2015, 115, 9801.

7 P. T. Tanev, M. Chibwe and T. J. Pinnavaia, Nature, 1994, 368, 321.

8 M. Ibn-Elhaj and M. Schadt, Nature, 2001, 410, 796.

9 R. R. Li, P. D. Dapkus, M. E. Thompson, W. G. Jeong, C. Harrison, P. M. Chaikin, R. A. Register and D. H. Adamson, Appl. Phys. Lett., 2000, 76, 1689.

10 G. Yang, X. Xiong and L. Zhang, J. Membr. Sci., 2002, 201, 161.

11 N. Takehiro, O. Ryusuke, N. Jin, A. Keiko, H. Junko, K. Nobuhito, S. Tetsuro, H. Masahiko and S. Masatsugu, Langmuir, 2002, 18, 5734.

12 V. V. K. Vendra, L. Wu and S. Krishnan, Nanomater. Life Sci., 2010, 1.

13 Y. Zhu, R. Sheng, T. Luo, H. Li, J. Sun, S. Chen, W. Sun and A. Cao, ACS Appl. Mater. Interfaces, 2011, 3, 2487.

14 P. A. Levkin, J. M. J. Frechet and F. Svec, Adv. Funct. Mater., 2010, 19, 1993.

15 P. Thevenot, W. Hu and L. Tang, Curr. Top. Med. Chem., 2011, 8, 270.

16 L. Montanaro, P. Speziale, D. Campoccia, S. Ravaioli, I. Cangini, G. Pietrocola, S. Giannini and C. R. Arciola, Future Microbiol., 2011, 6, 1329.

17 I. Francolini and G. Donelli, FEMS Immunol. Med. Microbiol., 2010, 59, 227. 
18 J. R. Johnson, M. A. Kuskowski and T. J. Wilt, Ann. Intern. Med., 2006, 144, 116.

19 W. Fu, T. Forster, O. Mayer, J. J. Curtin, S. M. Lehman and R. M. Donlan, Antimicrob. Agents Chemother., 2010, 54, 397.

20 D. Campoccia, L. Montanaro and C. R. Arciola, Biomaterials, 2013, 34, 8533.

21 A. N. Zelikin, ACS Nano, 2010, 4, 2494.

22 S. N. Pandeya, S. Smitha, M. Jyoti and S. K. Sridhar, Acta Pharm., 2005, 55, 27.

23 P. Pakravan, S. Kashanian, M. M. Khodaei and F. J. Harding, Pharmacol. Rep., 2013, 65, 313.

24 I.-J. Kang, L.-W. Wang, T.-A. Hsu, A. Yueh, C.-C. Lee, Y.-C. Lee, C.-Y. Lee, Y.-S. Chao, S.-R. Shih and J.-H. Chern, Bioorg. Med. Chem. Lett., 2011, 21, 1948.

25 F. Degola, C. Morcia, F. Bisceglie, F. Mussi, G. Tumino, R. Ghizzoni, G. Pelosi, V. Terzi, A. Buschini, F. M. Restivo and T. Lodi, Int. J. Food Microbiol., 2015, 200, 104.

26 D. Mallinson, P. Alexiou, A. B. Mullen, M. Pelecanou, M. Sagnou and D. A. Lamprou, RSC Adv., 2016, 6, 24939.

27 H. Pervez, M. S. Iqbal, M. Y. Tahir, F.-H. Nasim, M. I. Choudhary and K. M. Khan, J. Enzyme Inhib. Med. Chem., 2008, 23, 848.
28 I. J. Kang, L. W. Wang, T. A. Hsu, A. Yueh, C. C. Lee, Y. C. Lee, C. Y. Lee, Y. S. Chao, S. R. Shih and J. H. Chern, Bioorg. Med. Chem., 2011, 21, 1948.

29 H. Pervez, N. Manzoor, M. Yaqub and K. M. Khan, J. Enzyme Inhib. Med. Chem., 2014, 29, 628.

30 X. M. Zhang, H. Guo, Z. S. Li, F. H. Song, W. M. Wang, H. Q. Dai, L. X. Zhang and J. G. Wang, Eur. J. Med. Chem., 2015, 101, 419.

31 D. A. Lamprou, J. R. Smith, T. G. Nevell, E. Barbu, C. R. Willis and J. Tsibouklis, J. Adv. Microsc. Res., 2010, 5, 137.

32 S. S. Latthe, C. Terashima, K. Nakata and A. Fujishima, Molecules, 2014, 19, 4256.

33 A. B. D. Cassie and S. Baxter, Trans. Faraday Soc., 1944, 40, 5461.

34 U. H. F. Bunz, Adv. Mater., 2006, 18, 973.

35 M. S. Park and J. K. Kim, Langmuir, 2004, 20, 5347.

36 M. Özkütük, C. Öğretir, T. Arslan, F. Kandemirli and B. Köksoy, J. Chem. Eng. Data, 2010, 55, 2714.

37 T. Ponnusamy, L. B. Lawson, L. C. Freytag, D. A. Blake, R. S. Ayyala and V. T. John, Biomatter, 2012, 2, 7. 